\title{
Reorganización y modernización de las Administraciones Públicas: sucesión laboral y despidos colectivos ${ }^{1}$
}

\section{Reorganization and modernization of the Public Administrations: labor succession and collective dismissals}

José Luis Monereo Pérez

Universidad de Granada (España)

ORCID: https://orcid.org/0000-0002-0230-6615 jmonereo@ugr.es

\section{NOTA BIOGRÁFICA}

Catedrático de Derecho del Trabajo y de la Seguridad Social de la Universidad de Granada. Presidente de la Asociación Española de Salud y Seguridad Social (AESSS). Árbitro del Sistema Extrajudicial de Resolución de Conflictos Laborales de Andalucía (SERCLA). Investigador Principal de diversos Proyectos de Investigación I+D+i del Ministerio de Ciencia y Tecnología, así como de Excelencia de la Junta de Andalucía. Miembro de los Consejos de Redacción de distintas Revistas Nacionales e Internacionales. Director de los Foros Aranzadi Social de Granada y Almería.

María Nieves Moreno Vida Universidad de Granada (España) ORCID: https://orcid.org/0000-0002-0600-8332 mnmvida@ugr.es

\section{NOTA BIOGRÁFICA}

Catedrática y Directora del Departamento de Derecho del Trabajo y de la Seguridad Social de la Universidad de Granada. Consejera del Consejo Económico y Social de Andalucía, como miembro del grupo de expertos en el ámbito socioeconómico dentro del Grupo Tercero (Decreto 4/2014, de 1 de julio). Investigadora Principal de múltiples Proyectos de Investigación I+D+i en materia de Seguridad Social y políticas de empleo. Evaluadora de la Agencia Nacional de Evaluación y Prospectiva (ANEP), para la evaluación de proyectos o actividades científicas.

Belén del Mar López Insua

Universidad de Granada (España)

ORCID: https://orcid.org/0000-0002-1248-6015

blinsua@ugr.es

\section{NOTA BIOGRÁFICA}

Profesora Contratada Doctora (Acreditada como Titular de Universidad) de Derecho del Trabajo y de la Seguridad Social de la Universidad de Granada. Miembro de la Junta Directiva de la Asociación Española de Salud y Seguridad Social (AESSS) y dentro de ella de su Comité Ejecutivo. Miembro permanente del

\footnotetext{
1 Artículo publicado en el marco del Proyecto de Investigación financiado por el INAP «Público y Privado en la gestión de los servicios públicos: reestructuración, externalización y reversión a la Administración».
} 
Consejo Asesor de Laborum. Revista de Derecho de la Seguridad Social. Responsable de la sección permanente sobre Crónica de Doctrina Judicial y Noticias Bibliográficas en la Revista Laborum de Derecho de la Seguridad Social.

\title{
RESUMEN
}

Los procesos de externalización implican numerosos problemas en la esfera iuslaboral, y de mayor envergadura cuando se trata de supuestos en los que estén implicados alguna Administración Pública o un ente público instrumental, porque, entre otras cosas, entra en juego directamente el interés público en el mantenimiento en condiciones de eficiencia del servicio público, los entes públicos tiene que respetar las garantías de acceso a los empleos públicos, existen límites presupuestarios, etcétera).

Tanto en el sector público fundacional y empresarial como en el sector público administrativo no cabe duda que ha incidido la supresión de la autorización administrativa previa en los despidos colectivos, en el sentido de determinar un intervencionismo administrativo menos intenso. Ahora bien, los despidos colectivos en el sector público comportan por su propia lógica interna un mayor peso de la intervención administrativa a distinto nivel o en distintos ámbitos. Al tiempo no sólo es el marco de referencia sino también -y en relación a ello- el carácter público de los fines que se pretenden, que se centrarían en la búsqueda de la mayor eficiencia de la entidad y organismo público a través de la reestructuración de plantillas laborales.

\section{PALABRAS CLAVE}

Reversión; sector público; despido colectivo; límites y garantías laborales.

\begin{abstract}
Outsourcing processes involve numerous problems in the labor sphere, and of greater scope when dealing with cases in which any Public Administration or an instrumental public entity is involved, because, among other things, the public interest in the public sphere directly comes into play. maintenance in conditions of efficiency of public service, public entities have to respect the guarantees of access to public jobs, there are budgetary limits, etc.).

Both in the foundational and corporate public sector and in the administrative public sector, there is no doubt that the elimination of prior administrative authorization in collective dismissals has impacted, in the sense of determining a less intense administrative interventionism. However, collective dismissals in the public sector involve, by their own internal logic, a greater weight of administrative intervention at different levels or in different areas. At the same time, it is not only the frame of reference but also -and in relation to it- the public nature of the intended purposes, which would focus on the search for greater efficiency of the entity and public body through the restructuring of work templates.
\end{abstract}

\section{KEYWORDS}

Reversion; public sector; collective dismissal; limits and labor guarantees.

\section{SUMARIO}

1. INTRODUCCIÓN. NORMATIVA SUCESORIA LABORAL Y REVERSIÓN DE SERVICIOS PÚBLICOS. 2. REESTRUCTURACIONES DE ENTES PÚBLICOS. LOS DESPIDOS COLECTIVOS EN EL SECTOR PÚBLICO (DISPOSICIÓN ADICIONAL 16. ${ }^{a}$ DEL ET Y NORMAS CONCORDANTES). REFERENCIAS BIBLIOGRÁFICAS.

\section{INTRODUCCIÓN. NORMATIVA SUCESORIA LABORAL Y REVERSIÓN DE SERVICIOS PÚBLICOS}

Es sabido que la multiplicación de las actividades de las Administraciones Públicas ha propiciado las políticas de gestión privada de servicios públicos en todos los niveles administrativos (central, autonómico y local). Esas prácticas se han extendido y más que desaparecer, como resulta visible, se vienen produciendo 
flujos y reflujos, es decir, procesos de atribución de gestión indirecta por entidades privadas, y de ésta a su retorno o reversión a manos públicas (fenómeno de republificación institucional de la gestión -en el ámbito local, remunicipalización de la gestión de servicios municipales-; no de la titularidad del servicio público que siempre ha sido pública). La recuperación de la gestión del servicio público se puede instrumentar a través de la integración directa en la Administración Pública actuante, o a través de entes instrumentales (como es el caso de las sociedades mercantiles) ${ }^{2}$. Todo ello bajo el presupuesto de que no necesariamente la eficacia es un atributo per se de la gestión directa pública o indirecta privada, sino que dependerá de las circunstancias concurrentes, sin obviar por ello la política del Derecho dirigida a revalorizar la gestión pública precisamente por su eficiencia y racionalización de costes de la gestión de los servicios públicos.

Los procesos de externalización implican numerosos problemas en la esfera iuslaboral, y de mayor envergadura cuando se trata de supuestos en los que estén implicados alguna Administración Pública o un ente público instrumental, porque, entre otras cosas, entra en juego directamente el interés público en el mantenimiento en condiciones de eficiencia del servicio público, los entes públicos tiene que respetar las garantías de acceso a los empleos públicos, existen límites presupuestarios, etcétera). A este respecto, hay que tener en cuenta la importante incidencia en esta materia de la Disposición Adicional vigésima sexta, «Limitaciones a la incorporación de personal laboral al sector público», de la Ley 3/2017, de 27 de junio, de Presupuestos Generales del Estado para el año 2017, conforme a la cual: «Uno. Con efectos desde la entrada en vigor de esta Ley y vigencia indefinida, las Administraciones Públicas del artículo 2 del texto refundido de la Ley del Estatuto Básico del Empleado Público, aprobado por el Real Decreto Legislativo 5/2015, de 30 de octubre, no podrán considerar como empleados públicos de su artículo 8, ni podrán incorporar en dicha condición en una Administración Pública o en una entidad de derecho público: a) A los trabajadores de los contratistas de concesiones de obras o de servicios públicos o de cualquier otro contrato adjudicado por las Administraciones Públicas previstas en el artículo 2.3 de la Ley 40/2015, de 1 de octubre, de Régimen Jurídico del Sector Público, cuando los contratos se extingan por su cumplimiento, por resolución, incluido el rescate, o si se adopta el secuestro o intervención del servicio conforme a la legislación de contratos del sector público que resultase aplicable a los mismos. b) Al personal laboral que preste servicios en sociedades mercantiles públicas, fundaciones del sector público, consorcios, en personas jurídicas societarias o fundacionales que vayan a integrarse en una Administración Pública». Esta norma impide que los trabajadores que presten servicios para las empresas descritas en los apartados a) y b) puedan considerarse como «empleados públicos» ex art. 8 EBEP, y por tanto impide que puedan considerarse «indefinidos no fijos», que era la calificación que hasta el momento los tribunales han aplicado a los trabajadores que han sido objeto de alguno de los procesos señalados y a los que había de aplicarse el art. $44 \mathrm{ET}^{3}$.

La supresión por el apartado uno de la Disp. Final $42 .^{\text {a }}$ de la Ley 6/2018, de 3 de julio, de PGE para el año 2018 del último párrafo del apartado uno de la Disp. Adic. 26. ${ }^{a}$ sexta de la LPGE para el año 2017, que decía «Al personal referido en los apartados anteriores le serán de aplicación las previsiones sobre sucesión de empresas contenidas en la normativa laboral», no significa, sin embargo, que en estos casos no se aplique la Directiva 2001/23 sobre transmisión de empresa, ni la doctrina jurisprudencial establecida al respecto por el Tribunal deJusticia de laUnión Europea, ni la normativa de transposición en nuestro ordenamiento interno contenida en el art. $44 \mathrm{ET}$ (cfr. Artículo 130. Información sobre las condiciones de subrogación en contratos de trabajo, de laLey 9/2017, de 8 de noviembre, de Contratos del Sector Público, por la que se transponen al ordenamiento jurídico español las Directivas del Parlamento Europeo y del Consejo 2014/23/ UE y 2014/24/UE, de 26 de febrero de $2014^{4}$.

2 Sobre la problemática iuslaboral de los entes instrumentales, véase MONEREO PÉREZ, J. L. (2015): "Las reestructuraciones en el sector público y su incidencia en el empleo público laboral”, CASTILLO BLANCO, F. A. y MONEREO PÉREZ, J. L. (dirs. y coords.): Reestructuración de las Públicas: Aspectos administrativos y laborales, Granada: Comares, pág. 211 y ss.

${ }^{3}$ MONEREO PÉREZ, J. L. (2017): “Tratamiento jurídico-laboral de la transmisión de empresas: funciones y disfunciones ante los «casos difíciles» en la jurisprudencia reciente", en Trabajo y Derecho, núm. 5.

4 «1. Cuando una norma legal un convenio colectivo o un acuerdo de negociación colectiva de eficacia general, imponga al adjudicatario la obligación de subrogarse como empleador en determinadas relaciones laborales, los servicios dependientes del órgano de contratación deberán facilitar a los licitadores, en el propio pliego, la información sobre las condiciones de los contratos de los trabajadores a los que afecte la subrogación que resulte necesaria para permitir una exacta evaluación de los costes laborales que implicará tal medida, debiendo hacer constar igualmente que tal información se facilita en cumplimiento de lo previsto en el presente artículo. A estos efectos, la empresa que viniese efectuando la prestación objeto del contrato a adjudicar y que tenga la condición de empleadora de los trabajadores afectados estará obligada a proporcionar la referida información al órgano de contratación, a requerimiento de este. Como parte de esta información en todo caso se deberán aportar los listados del personal objeto de subrogación, indicándose: el convenio colectivo de aplicación y los detalles de categoría, tipo de contrato, jornada, fecha de antigüedad, 
Además, la Disp. Adic. 34. ${ }^{\text {a }}$ de la LPGE para el año 2017 («Exigencia de responsabilidades en las Administraciones Públicas y entidades dependientes de las mismas por la utilización de la contratación laboral»), en su apartado Dos, tras establecer la responsabilidad de los órganos competentes en materia de personal en cada una de las Administraciones Públicas y en las entidades que conforman su Sector Público Instrumental respecto del cumplimiento de la normativa laboral (evitando en especial cualquier tipo de irregularidad en la contratación laboral temporal que pueda dar lugar a la conversión de un contrato temporal en indefinido no fijo), establece que estos órganos de personal no podrán atribuir la condición de indefinido no fijo a personal con un contrato de trabajo temporal, ni a personal de empresas que a su vez tengan un contrato administrativo con la Administración respectiva, salvo cuando ello se derive de una resolución judicial. Esta norma se recoge nuevamente en la Disp. Adic. $43 .^{a}$ de la Ley 6/2018, de 3 de julio, de PGE para el año 2018.

Sin embargo, la STC de 31 de octubre 2018 (rec. 4710/2017) ha declarado la inconstitucionalidad de este apartado Uno de la Disp. Adic. 26. ${ }^{a}$ de la Ley 3/2017, de Presupuestos Generales del Estado para el año 2017 y de la parte del apartado Dos de la Disp. Adic. $34 .^{a}$ de la misma Ley, donde se hace referencia a «ni a personal de empresas que a su vez tengan un contrato administrativo con la Administración respectiva» (reiterado, sin embargo, como se ha dicho en la DA 43. ${ }^{a}$ de la LPGE para 2018). La declaración de inconstitucionalidad se produce por una cuestión de carácter formal, no por su contenido sino por haber sido incluidas en una norma, la Ley de Presupuestos, que no era la adecuada. Conforme a la doctrina del Tribunal Constitucional, «el contenido de las leyes de presupuestos está constitucionalmente determinado, a partir de su función como norma que ordena el gasto público (art. $134 \mathrm{CE}$ )» y, por tanto, «no tienen en ella cabida las modificaciones sustantivas del ordenamiento jurídico, a menos que éstas guarden la suficiente conexión económica (relación directa con los ingresos o gastos del Estado o vehículo director de la política económica del Gobierno) o presupuestaria (para una mayor inteligencia o mejor ejecución del presupuesto)». Considera el Tribunal Constitucional que, en este caso, el contenido de la DA 26. ${ }^{a}$ no se puede calificar como una medida de contención del gasto público [«tales trabajadores serán retribuidos por la Administración pública en cualquier caso, pues no a otra conclusión conduce la aplicación del régimen laboral (sucesión de empresas)»], sino que se trata de una medida regulatoria, de carácter sustantivo (se incorpora una precisión de lo dispuesto en el art. 8 EBEP), que de acuerdo con la doctrina consolidada de este Tribunal no puede encontrar acomodo en una ley de presupuestos.

El resultado es, por tanto, la supresión, por inconstitucional, de esta DA 26. ${ }^{a}$ Uno y de parte de la DA 34. a de la LPGE de 2017 y en consecuencia se vuelve a la situación anterior a esta Ley: en estos casos, los trabajadores deberán considerarse como indefinidos no fijos. No obstante, queda pendiente posiblemente la declaración de inconstitucionalidad de la Disp. Adic. 43. Dos de la LPGE para 2018, que prohíbe la declaración de un trabajador como indefinido no fijo sin previa declaración judicial (aspecto que, como ya se ha indicado, se recogía igualmente en la Disp. Adic. 34. Dos de la LPGE para 2017 y que también ha sido declarado inconstitucional).

vencimiento del contrato, salario bruto anual de cada trabajador, así como todos los pactos en vigor aplicables a los trabajadores a los que afecte la subrogación. La Administración comunicará al nuevo empresario la información que le hubiere sido facilitada por el anterior contratista. 2. Lo dispuesto en este artículo respecto de la subrogación de trabajadores resultará igualmente de aplicación a los socios trabajadores de las cooperativas cuando estos estuvieran adscritos al servicio o actividad objeto de la subrogación. Cuando la empresa que viniese efectuando la prestación objeto del contrato a adjudicar fuese un Centro Especial de Empleo, la empresa que resulte adjudicataria tendrá la obligación de subrogarse como empleador de todas las personas con discapacidad que vinieran desarrollando su actividad en la ejecución del referido contrato. 3. En caso de que una Administración Pública decida prestar directamente un servicio que hasta la fecha venía siendo prestado por un operador económico, vendrá obligada a la subrogación del personal que lo prestaba si así lo establece una norma legal, un convenio colectivo o un acuerdo de negociación colectiva de eficacia general. 4. El pliego de cláusulas administrativas particulares contemplará necesariamente la imposición de penalidades al contratista dentro de los límites establecidos en el artículo 192 para el supuesto de incumplimiento por el mismo de la obligación prevista en este artículo. 5. En el caso de que una vez producida la subrogación los costes laborales fueran superiores a los que se desprendieran de la información facilitada por el antiguo contratista al órgano de contratación, el contratista tendrá acción directa contra el antiguo contratista. 6. Asimismo, y sin perjuicio de la aplicación, en su caso, de lo establecido en el artículo 44 del texto refundido de la Ley del Estatuto de los Trabajadores, aprobado por Real Decreto Legislativo 2/2015, de 23 de octubre, el pliego de cláusulas administrativas particulares siempre contemplará la obligación del contratista de responder de los salarios impagados a los trabajadores afectados por subrogación, así como de las cotizaciones a la Seguridad social devengadas, aún en el supuesto de que se resuelva el contrato y aquellos sean subrogados por el nuevo contratista, sin que en ningún caso dicha obligación corresponda a este último. En este caso, la Administración, una vez acreditada la falta de pago de los citados salarios, procederá a la retención de las cantidades debidas al contratista para garantizar el pago de los citados salarios, y a la no devolución de la garantía definitiva en tanto no se acredite el abono de éstos». 
La reversión de la gestión del servicio es con mucho el supuesto más complejo ${ }^{5}$. Interesa realzar que en los supuestos de reversión de contratas o concesiones administrativas siempre se han suscitado arduos problemas y con muchas oscilaciones en la doctrina judicial y, desde luego, científica, en lo que se refiere a las transmisiones de empresas, despidos colectivos, etcétera. En el momento actual respecto a transmisión de empresa en este escenario (Directiva 2001/23/CE; y art. 44 del ET), cabe diferenciar diversos supuestos:

1. En primer lugar, que la transmisión actualice el supuesto de hecho típico de la norma aplicable, a saber: Que haya transmisión de elementos instrumentales o infraestructura necesaria para el ejercicio o continuidad de la empresa u organización productiva (la integración de la noción de entidad económica). Su concurrencia determina la aplicación ope legis del art. 44 del ET ${ }^{6}$. Si hay transmisión de empresa o unidad productiva (lo que no cabe equiparar al supuesto excluido en la Directiva 2001/23/CE de una mera reorganización administrativa interna ni del simple traspaso de funciones administrativas entre autoridades públicas administrativas) se convendrá, pues, en que hay que aplicar la normativa legal sucesorio laboral con todas sus consecuencias (por ejemplo, SSTS de 16 de octubre de 2013, rec. 1640/12; 30 de diciembre de 2013, rec. 3633/2012; STSJ Andalucía de 13 de mayo de 2015, rec. 498/2015; 30 de mayo de 2011, rec. 2192/2010; 11 de julio de 2011, rec. 2861/2010). En los supuestos de reversión a la Administración Pública hay que señalar lo siguiente: En caso de trabajadores de la empresa anterior adjudicataria del servicio público con contrato de duración indefinida se considerará aplicable la figura de los indefinidos no fijos, y aplicando el art. 44 del ET con todas las consecuencias previstas en el mismo. Es manifiesto que si, al contrario, se trata de contratos temporales la sucesión laboral operará en los mismos términos del contrato estipulado sin afectar a su vigencia originaria.

$2{ }^{\circ}$ El segundo supuesto relevante se puede plantear en los siguientes términos: que pese a ello -al no existir transmisión de elementos instrumentales necesarios para el ejercicio de la actividad o servicio- se esté ante una entidad económica donde lo relevante no sea la infraestructura sino la mano de obra adscrita a la actividad organizada, y entonces podría concurrir la doctrina de la sucesión o asunción de plantilla con el mismo resultado de aplicar la normativa sucesoria laboral legal en la transmisión de empresa [en un sector en el que la actividad se basa esencialmente en la mano de obra -y no tanto en los elementos de activo, materiales o inmateriales- la identidad de una entidad económica no puede mantenerse si el supuesto cesionario no se hace cargo de la mayor parte de su plantilla (véase, en este sentido, SSTJUE 20 de enero de 2011, CLECE, C-463/09, apartado 41; 10 de diciembre de 1998, Hernández Vidal, C-127/1996; 24 de enero de 2002, Temco, entre otras muchas) ${ }^{7}$, y SSTS 27 de octubre de 2004, RJ 7202; de 12 de julio de 2010, rec. 2300/09; de 7 de diciembre de 2011, rec. 4665/10; 19 de mayo de 2015, rec. núm. 358/2014; 9 de febrero de 2016, rec. 400/2014, entre otras)] $]^{8}$. En tal caso, se aplica también el art. 44 del ET, al considerarse que el cambio de titularidad ha tenido por objeto una "entidad económica». Este criterio aporta tan sólo una cobertura muy limitada y condicionada a la decisión voluntaria y discrecional de la empresa o entidad cesionaria o a quien revierte la actividad o servicio objeto de contratación, pues, en última instancia, de ella depende la opción unilateral de asumir un número esencial o sustancialmente relevante del personal laboral de la empresa contratista o concesionaria. Y a sabiendas de que ello supondría la aplicación ex lege del conjunto de garantías previstas en el art. 44 del ET y demás normas del grupo regulador de las garantías sociolaborales en la sucesión de empresas: la sucesión de plantilla es un supuesto específico de transmisión de empresa ex art. 44 del ET, esto es, la sucesión legal de empresa se produce por sucesión de

${ }^{5}$ RODRÍGUEZ ESCANCIANO, S. (2015): "Reorganización y extinción de estructuras o unidades administrativas", en CASTILLO BLANCO, F. A. y MONEREO PÉREZ, J. L. (dirs. y coords.): Reestructuración de las Administraciones Públicas: Aspectos Administrativos y Laborales, págs. 343-368. Granada: Comares.

6 Incluidos los supuestos de contratas o concesiones materializadas que implican traspasos de infraestructura empresarial. Así, por ejemplo, STJUE de 20 de noviembre de 2003, Abler C-340/01, relativa a los cambios de titularidad del comedor de un hospital; STJUE 26 de noviembre de 2015, Asunto Aira Pascual, C-509/2014; SSTS 9 de febrero de 2016, rec. 400/2014; 13 de enero de 2016 , rec. 615/2015; 19 de mayo de 2015, rec. núm. 358/2014; 21 de abril de 2015, rec. núm. 91/2014.

7 STJUE de 20 de enero de 2011 (Asunto C-463/09), entiende que la Directiva 2001/23/CE «no se aplica a una situación en la que un Ayuntamiento, que había encargado la limpieza, decide poner fin al contrato celebrado con ésta y realizar por sí mismo los trabajos de limpieza de dichas dependencias, contratando para ello nuevo personal». También nuestro Tribunal Supremo, entiende que la reversión al Ayuntamiento de una Escuela de Música por abandono del concesionario no hay sucesión empresarial ex art. 44 del ET, porque el Ayuntamiento no continúa la actividad.

8 Para la fenomenología de supuestos subrogación y reversión del servicio a las Administraciones Públicas, con o sin (sucesión de plantilla) infraestructura material, y su recepción en la doctrina judicial, puede consultarse el repertorio de sentencias recogido en ARETA MARTÍNEZ, M. y SEMPERE NAVARRO, A. V. (2017): Sucesión de empresa: contratas, subcontratas y otros supuestos, Madrid: Francis Lefebvre, pág. 64 y ss.; MARTíNEZ SALDAÑA, D. (coord.): La sucesión de empresa, cit., pág. 135 y ss. 
plantilla. Por ello convendría realizar una interpretación extensiva de la noción de «entidad económica» que permitiera incluir a los supuestos de cambio de titularidad en contratas o concesiones administrativas cuyo objeto son actividades o servicios desmaterializados (en este sentido el esfuerzo interpretativo reflejado en la jurisprudencia del TJUE, siendo en sí mismo muy importante, resulta todavía insuficiente y se ha quedado a medio camino para extraer todas las consecuencias respecto a las empresas desmaterializadas del sector terciario; a medio camino porque debería incluirse en el supuestos de hecho de la normativa sucesoria -con las especialidades que se consideren pertinentes-, de manera que se generalizaría la aplicación del sistema de garantías sociolaborales en los supuestos de cambio de titularidad de empresas desmaterializadas, que son las propias del sector terciario, sin tener que recurrir a la doctrina de la "sucesión de plantilla»); o, en otro caso, de lege ferenda incluir expresamente estos cambios de titularidad en el art. 44 del ET dotándolos de las peculiaridades que se estimen pertinentes. Y, en ambos casos, prescindiendo del criterio de la sucesión o asunción voluntaria por el nuevo titular de una parte esencial de la plantilla como condictio iuris para la aplicación automática e ipso iure del sistema de garantías sociolaborales en la transmisión de empresa ${ }^{9}$.

3..$^{\circ}$ Ante las dificultades de la subrogación convencional ${ }^{10}$ en los supuestos de reversión de servicios públicos externalizados para su gestión directa por la Administración actuante no son pocos los convenios colectivos sectoriales que ya establecen previsiones específicas al respecto, pero con arduos problemas de aplicación práctica (por ej. art. 26.2 del XI Convenio Colectivo de ámbito estatal de centro de asistencia y educación infantil de 2010; art. 17 del I Convenio colectivo del sector de limpieza de edificios y locales de 2013; también, como ejemplo paradigmático, art. 50 del Convenio General del sector de saneamiento público, de limpieza viaria, riegos, recogida, tratamiento y eliminación de residuos, limpieza y conservación de alcantarillado, pactado en 2013).

En este contexto hay que tener en cuenta el cambio de criterio del Tribunal Supremo al desligar la subrogación convencional (esto es, en virtud de convenio colectivo, que comporta en sí misma sucesión de plantilla) del sistema de garantías ex art. 44 del ET, en relación con la Directiva 2001/23, de 12 de marzo, sobre garantías de los derechos de los trabajadores en las transmisiones de empresas (SSTS de 7 de abril de 2016, rec. 2269/2014; 3 de mayo de 2016, rec. 3165/2014). No resulta baladí dejar constancia de que incluso en supuestos de empresas de servicios con elementos materializados necesarios para el ejercicio de la actividad empresarial el Tribunal Supremo no ha apreciado la existencia de transmisión de empresa: así, STS de 9 de diciembre de 2016, rec. 1674/2015 (reversión de un servicio de comedor escolar del IES «Universidad Laboral» a la Junta de Castilla-La Mancha); STS de 12 de julio de 2016, rec. $349 / 2015$ (Caso «Liceo»); STS 26 de enero de 2017, rec. 3847/2015 y 2982/2015 (relativas a la reversión del centro «Universidad laboral»). Doctrina discutible partiendo en términos de principio del hecho mismo de que se entregó la infraestructura necesaria para la continuación del servicio y que, por tanto, se debería estimar la existencia de sucesión de empresa en la línea que estableciera la STJUE de 20 de noviembre de 2003, caso Abler C-340/01, conforme a la cual la restauración colectiva no puede considerarse como una actividad que se base esencialmente en la mano de obra, en la medida en que exige unos equipamientos importantes propios del servicio desplegado ${ }^{11}$.

\footnotetext{
9 MONEREO PÉREZ, J. L. (1999): La noción de empresa en el Derecho del Trabajo y su cambio de titularidad. Estudio del ordenamiento interno y comunitario, Madrid: Ibidem Ediciones; Íd. (2010): "Dimensión laboral de la transmisión de empresa y nuevas formas de organización productiva", en Tribuna Social, núms. 238-239-240; igualmente, y con cuidada argumentación, VICENTE PALACIO, A. (2016): Empresas multiservicios y precarización del empleo. El trabajador subcedido, Madrid: Atelier.

10 Vía convenio colectivo -normalmente de ámbito sectorial y no generalizada- que opera como fuente de Derecho objetivo realizando un tratamiento singular del supuesto de hecho de la subrogación laboral y sus consecuencias jurídicas, y siempre que la Administración actuante esté incluida en su ámbito de aplicación (lo que no debe confundirse con la exigencia de una necesaria firma de la norma colectiva por el ente público concernido). La cuestión no está exenta de litigiosidad (v. gr., la problemática del convenio aplicable a los trabajadores afectados; la vinculación de la Administración al convenio colectivo). Pero ante una subrogación o sucesión convencional que la imponga la Administración o ente público administrativo actuante ha de atenerse al cumplimiento de la normativa laboral aplicable (art. 7 del EBEP; art. 130 de la Ley 9/2017, de 8 de noviembre, de Contratos del Sector Público. Puede consultarse MONEREO PÉREZ, J. (1986): "Continuidad de las relaciones de trabajo en la gestión indirecta de servicios y actividades. El cambio de titularidad en las contratas y en las concesiones administrativas", en Relaciones Laborales, núm. 7; íd.: "Dimensión laboral de la transmisión de empresa y nuevas formas de organización productiva", en Tribuna Social, núm. 239 (2010); y RODRÍGUEZ ESCANCIANO, S. (2013): Despidos y otras medidas de (re)estructuración de plantillas en el sector público, Madrid: lustel, pág. 328 y ss.

11 Véase, en este sentido, el Comentario de BELTRÁN DE HEREDIA RUÍZ, I. (2017): "Una reversión del servicio de comedor escolar no puede describir una sucesión de empresa? ¿Ni a la luz del caso Abler", en Una mirada crítica a las relaciones, Blog de Derecho del Trabajo y de la Seguridad Social. URL: https://ignasibeltran.com/2017/03/22/una-reversion-del-servicio-de-comedor-escolarno-puede-describir-una-sucesion-de-empresa-ni-a-la-luz-del-caso-abler/.
} 
Es importante destacar aquí la reciente Sentencia del TJUE de 11 de julio de 2018, asunto C-60/17, Somoza Hermo. Esta Sentencia da respuesta parcial a la cuestión prejudicial formulada por la Sala de lo Social del TSJ de Galicia (Auto de 30 de diciembre de 2016), relativa a las obligaciones de las empresas cedente y cesionaria cuando se produce una sucesión de empresa. La tesis mantenida por el Tribunal Supremo ha sido hasta ahora que en el caso de subrogaciones convencionales la norma aplicable es el convenio colectivo y no el art. 44 del ET, por lo que no se aplican directamente las garantías previstas en esta norma, sino las que se hayan determinado en el convenio colectivo. Frente a la misma, la STJUE de 11 de julio de 2018 (asunto C-60/17) establece que el artículo 1, apartado 1, de la Directiva 2001/23/CE del Consejo, de 12 de marzo de 2001, sobre la aproximación de las legislaciones de los Estados miembros relativas al mantenimiento de los derechos de los trabajadores en caso de [transmisiones] de empresas, de centros de actividad o de partes de empresas o de centros de actividad, debe interpretarse en el sentido de que esta Directiva se aplica a una situación en la que un arrendatario de servicios ha resuelto el contrato de prestación de servicios de vigilancia de instalaciones celebrado con una empresa y, a efectos de la ejecución de la prestación, ha celebrado un nuevo contrato con otra empresa que se hace cargo, en virtud de un convenio colectivo, de una parte esencial, en términos de número y de competencias, del personal que la primera empresa destinaba a la ejecución de dicha prestación, siempre y cuando la operación vaya acompañada de la transmisión de una entidad económica entre las dos empresas afectadas (reitera aquí su doctrina de que «una actividad de vigilancia de un museo (...), que no exige el uso de materiales específicos, puede considerarse una actividad que descansa fundamentalmente en la mano de obra y, por consiguiente, un conjunto de trabajadores que ejerce de forma duradera una actividad común de vigilancia puede, a falta de otros factores de producción, constituir una entidad económica»).

EI TJUE no ha dado respuesta, por considerar que no es competente para ello, a la segunda pregunta, relativa si el artículo 3, apartado 1, párrafo segundo, de la Directiva 2001/23 debe interpretarse en el sentido de que se opone a que, en virtud de un convenio colectivo, se excluya la obligación de que el cedente y el cesionario de la entidad económica afectada respondan solidariamente de las obligaciones, incluidas las retributivas, derivadas de los contratos de trabajo anteriores a la cesión de dicha entidad. No obstante, si la subrogación convencional (que entraña la «sucesión de plantilla») entra dentro del ámbito de aplicación de la Directiva, la consecuencia directa es que se aplica la normativa interna de transposición de ésta, es decir, el art. 44 del ET. En este sentido, se pronuncia la STS 873/2018, de 27 de septiembre de 2018, en relación con un supuesto de sucesión de contratas en el servicio de limpieza, CLECE, en la que, rectificando doctrina para concordarla con la STJUE de 11 de julio de 2018, establece que, pese a la previsión contraria del convenio colectivo, el nuevo empresario responde de las deudas del anterior en los términos del art. 44.3 del ET.

$4 .^{\circ}$ En una cuarta fenomenología de supuestos, cabría pensar en que no se esté en ninguno de los supuestos anteriores, y en tal caso, haya todavía la posibilidad de aplicar las previsiones -conforme a la Ley aplicable- del pliego de condiciones administrativas en la contratación pública ${ }^{12}$.Para este último supuesto de subrogación o sucesión laboral por acto de autoridad contractual instrumentado a través de las condiciones generales de la contratación en las que se resuelve técnicamente los pliegos de cláusulas administrativas, véase STS 30 de abril de 2014, rec. 1416/2013, y en relación a ello discutiendo la obligación de subrogación sin apoyo legal o en las condiciones generales de la contratación administrativa (pliegos de cláusulas de contratación, STS 16 de marzo de 2015, rec. 1009/2014). En todo caso hay que tener en cuenta que el art. 98 de la LCSP (Ley 9/2017, de 8 de noviembre, de Contratos del Sector Público, por la que se transponen al ordenamiento jurídico español las Directivas del Parlamento Europeo y del Consejo 2014/23/ UE y 2014/24/UE, de 26 de febrero de 2014) contempla los «supuestos de sucesión de contratista», y que deja bien nítidamente que «la obligación de subrogarse en las relaciones laborales derivadas de la ejecución de un contrato, cuando un contratista sucede a otro en ella, no deriva del contrato mismo sino de las normas laborales, normalmente de los convenios colectivos que se encuentren vigentes en el sector de actividad laboral de que se trate». En tal caso, resulta obvia la remisión implícita del art. 98 de la LCSP al sistema legal de garantías laborales previsto en el art. 44 del ET, norma de transposición en Derecho interno de la Directiva 2001/23/CE y que, por tanto, ha de interpretarse con arreglo a ella, sin perjuicio de poder incluir una normativa más favorables (art. 8 de la Directiva).

${ }^{12}$ La sucesión laboral del empleador público puede venir impuesta en el pliego de condiciones. En tal caso se configura una «subrogación por vía contractual administrativa». 
De cualquier modo, la regulación que puedan contener los pliegos de contratación administrativa no es ilimitada. Por un lado, no pueden impedir la aplicación ex lege de las garantías previstas en la normativa laboral (señaladamente, organizadas alrededor de su eje, el art. 44 del ET). Por otro lado, se plantea el problema de si los pliegos de contratación pueden imponer la subrogación al margen de la normativa legal, lógicamente en supuestos que no son subsumibles en el art. 44 del ET. Aquí parece existir una solución contrapuesta desde la doctrina administrativista y la jurisprudencia reiterada del Tribunal Supremo. Desde aquélla se afirma que de no existir convenio colectivo, el pliego de cláusulas administrativas no podría, en principio, establecer la obligación de subrogación ex novo, toda vez que -se afirma- afectaría a terceros (trabajadores de la empresa saliente), y excedería del ámbito administrativo y de la relación jurídica entre la Administración y el contratista. Sin embargo, para la doctrina del Tribunal Supremo, Sala de lo Social, es posible establecer este tipo de subrogación independiente y fuera de los supuestos típicos ex art. 44 del ET, pues la experiencia jurídica de la contratación administrativa contempla la realidad de su establecimiento en el pliego de condiciones aunque no sea muy frecuente (SSTS de 20 de septiembre de 2010, rec. 17/2010, y de 4 de junio de 2013, rec. 58/2012) ${ }^{13}$.

$5 .^{\circ}$ Es posible que no estándose ante ninguno de los supuestos anteriores, se produzca una sucesión contractual mediante acuerdo entre la empresa cedente y cesionaria, aun no concurriendo los requisitos del art. 44 del ET (aunque no exista convenio colectivo o pliego de cláusulas administrativas que la imponga con amparo legal, ni tampoco «sucesión de plantilla»). Se trata de una subrogación o sucesión laboral que opera una típica cesión de contrato de Derecho común, cuya validez ha sido admitida por la jurisprudencia del Tribunal Supremo, señaladamente en relación a las empresas de handling (STS 29 de febrero de 2000, entre otras), que constituye una modificación subjetiva de los contratos de trabajo por cambio del empleador y que exigiría necesariamente el consentimiento de los trabajadores afectados en aplicación modalizada del art. 1205 del Código Civil.

En este contexto problemático, la STJUE de 26 de noviembre de 2015, asunto C-509/2014, ADIF/AIgeposa Terminales Ferroviarios S. L., resulta clarificadora de la posición actual del Alto Tribunal comunitario respecto a la identificación y delimitación del objeto de la transmisión que actualiza el supuesto de hecho de la normativa sucesoria laboral, pues distingue entre reversión de actividad que se basa esencialmente en el equipamiento o infraestructura material y reversión de actividad sin ese equipamiento. En el primer supuesto entiende que se ha de aplicar la Directiva 2001/23 y la correspondiente normativa de transposición interna. El art. 1.1 de la Directiva 2001/23, acota su ámbito de aplicación indicando que se aplicará a de empresas, de centros de actividad o de partes de empresas o centros de actividad a otro empresario como resultado de una cesión contractual o de una fusión. Precisando que se considerará transmisión a efectos de la Directiva la de una entidad económica que mantenga su identidad, entendida como un conjunto de medios organizados, a fin de llevar a cabo una actividad económica, ya fuere esencial o accesoria, por un lado, y por otro, que será aplicable a empresas tanto públicas como privadas que ejerzan una actividad económica, con o sin ánimo de lucro (precisando, que la «reorganización administrativa» de las autoridades públicas administrativas y el traspaso de funciones administrativas entre autoridades públicas administrativas no constituirán una transmisión a efectos de la presente Directiva) ${ }^{14}$.

La normativa de transposición en el Derecho interno establece que se considerará que existe sucesión de empresa cuando la transmisión afecte a una entidad económica que mantenga su identidad, entendida como un conjunto de medios organizados a fin de llevar a cabo una actividad económica, esencial o accesoria (art. 44.2 del ET). En el sistema del art. 44 del ET el objeto de la transmisión puede quedar integrado por la empresa como organización socioeconómica de una actividad productiva determinada (o complejo de actividades productivas), siendo lo transmitido una unidad organizativa empresarial apta para el ejercicio de la actividad productiva después de consumarse el acto productor del cambio de titularidad. A efectos del art. 44 del ET no interesa meramente la empresa, según el modelo clásico, como explotación, negocio o industria, es decir, como objeto del Derecho en términos de complejo de bienes organizados, sino, más

13 Sobre esta tensión subyacente entre las lógicas administrativa y laboral de percepción de la cuestión controvertida, véase la nítida exposición al respecto de CASTILLO BLANCO, F. (2016): "Remunicipalización de servicios locales y situación del personal de los servicios públicos”, en El Cronista del Estado Social y Democrático de Derecho, núm. 58-59, Iustel, febrero-marzo, apartado IV («Las previsiones contenidas en la legislación contractual publica y su alcance»).

14 Ahora bien, si hay transmisión de empresa en el sentido de la Directiva 2001/23/CE y de la normativa interna de transposición ex art. 44 del ET, en la que quede implicada un ente u organismo de Derecho público deberá aplicarse, en principio, el sistema de garantías previsto en dicho grupo normativo. Así, por ejemplo, SSTJUE de 29 de julio de 2010, Asunto UGT-FSP contra Ayuntamiento de la Línea de la concepción; 12 de febrero de 2009, Asunto Klarenberg. 
complejamente, como unidad de trabajo susceptible de tener vida propia en la realización de determinados fines técnicos (de producción, de cambo o de servicios para el mercado) ${ }^{15}$.

Pues bien, en el caso planteado en la STJUE referenciada -resultante de una cuestión prejudicial-ADIF es una empresa pública titular del servicio de manipulación de unidades de transporte intermodal en la terminal de Bilbao. Este servicio se presta a Renfe Operadora. Mediante un contrato de gestión de servicios públicos, ADIF externalizó la gestión de dicho servicio, adjudicándola a la empresa Algeposa. Algeposa prestaba este servicio en las instalaciones de ADIF con grúas propiedad de esta última. Ulteriormente, ADIF comunicó a Algeposa que no deseaba prorrogar la contrata, ya que prestaría ella misma el servicio con su propio personal. ADIF comunicó también a Algeposa su negativa a subrogarse en los derechos y obligaciones de ésta frente a su personal. Como consecuencia de esta situación, Algeposa procedió a un despido colectivo por causas productivas de varios trabajadores, entre ellos el demandante (Sr. Aira Pascual), que antes estaba adscrito a la ejecución de la contrata celebrada con ADIF.

El Tribunal Superior de Justicia de la Comunidad Autónoma del País Vasco decidió suspender el procedimiento y plantear al Tribunal de Justicia la siguiente cuestión prejudicial: «El art. 1.[1.]b) de la Directiva 2001/23, en relación con su art. 4.1, ¿se opone a una interpretación de la legislación española destinada a darle efectividad, que excluya del deber de subrogación por el hecho de que una empresa del sector público, titular de un servicio inherente a su propia actividad y que precisa relevantes medios materiales, que ha venido realizando mediante contrata, imponiendo al contratista el uso de esos medios de su propiedad, decide no prorrogar la contrata y asumir directamente su realización o ejecución, valiéndose de personal propio, excluyendo al que la contratista empleaba, de tal modo que el servicio se sigue llevando a cabo sin más cambio que el que proviene de la sustitución de los trabajadores que desarrollan la actividad y su sujeción a un empresario diferente?».

En el proceso de decisión de la cuestión prejudicial el TJUE parte de la premisa constituida por los anteriores pronunciamientos del propio TJUE, indicando que ha declarado que la circunstancia de que el cesionario sea un organismo de Derecho público no permite excluir la existencia de una transmisión comprendida en el ámbito de aplicación de la Directiva 2001/23/CE (véase, en este sentido, la Sentencia CLECE, C-463/09, apartado 26 y jurisprudencia allí citada). Por tanto, el hecho de que la persona jurídica de que se trata en el litigio principal sea una empresa pública titular de un servicio público no la excluye del ámbito de aplicación de la Directiva 2001/23/CE. En segundo lugar, atiende al alcance de la normativa sucesoria ex art. 1 de la Directiva 2001/23/CE y de la normativa nacional aplicable, precisando que a este respecto, de una jurisprudencia reiterada del Tribunal de Justicia se desprende que el ámbito de aplicación de esa Directiva abarca todos los supuestos de cambio, en el marco de relaciones contractuales, de la persona física o jurídica responsable de la explotación de la empresa, que por este motivo asume las obligaciones del empresario frente a los empleados de la empresa, sin que importe si se ha transmitido la propiedad de los elementos materiales (véanse las sentencias Abler y otros, C-340/01, apartado 41, y CLECE, C-463/09, apartado 30). EI TJUE ha considerado asimismo que la Directiva 2001/23/CE es aplicable a una situación en la que una empresa que confía a otra empresa la ejecución efectiva de determinadas tareas decide poner fin al contrato que la vincula a ésta y ejecutar por sí misma esas tareas (véase, en este sentido, la sentencia CLECE, C-463/09, apartado 31). Es así que se desprende que no cabe excluir que la Directiva 2001/23/CE sea aplicable a una situación en la que una empresa pública, titular de una actividad económica de manipulación de unidades de transporte intermodal, confía mediante un contrato de gestión de servicios públicos la explotación de esa actividad a otra empresa, y posteriormente decide poner fin a dicho contrato y explotar ella misma esa actividad con su propio personal (fj. 25-30).

Por otra parte, en esta situación conflictiva se debe destacar que la actividad económica de que se trata (el servicio de manipulación de unidades de transporte intermodal), no puede considerarse una actividad esencialmente basada en la mano de obra, ya que requiere un equipamiento importante (por consiguiente, no es un problema de sucesión de plantilla en supuestos de cambio de titularidad, en el sentido de la STJUE 20.1. 2011, asunto CLECE, C-463/09, apartado 41), sino un típico supuesto de cambio de titularidad de una entidad económica de base material, donde resulta fundamental la infraestructura material, equipamiento e instalaciones.

Pero inequívocamente el fallo -que expresa lógicamente la decisión del Alto Tribunal sobre la cuestión prejudicial planteada- no deja sombra de duda (por su misma fisonomía clásica) respecto a la pertinente

15 MONEREO PÉREZ, J. L. (1999).: La noción de empresa en el Derecho del Trabajo y su cambio de titularidad. Estudio del ordenamiento interno y comunitario, Madrid: Ibidem, págs. 60 y 66, passim. 
aplicación de la normativa sucesoria. En efecto, el TJUE declara que «en virtud de todo lo expuesto»: «El art. 1.1 de la Directiva 2001/23/CE del Consejo, de 12 de marzo de 2001, sobre la aproximación de las legislaciones de los Estados miembros relativas al mantenimiento de los derechos de los trabajadores en caso de [transmisiones] de empresas, de centros de actividad o de partes de empresas o de centros de actividad, debe interpretarse en el sentido de que está comprendida en el ámbito de aplicación de esa Directiva una situación en la que una empresa pública, titular de una actividad económica de manipulación de unidades de transporte intermodal, confía mediante un contrato de gestión de servicios públicos la explotación de esa actividad a otra empresa, poniendo a disposición de ésta las infraestructuras y el equipamiento necesarios de los que es propietaria, y posteriormente decide poner fin a dicho contrato sin asumir al personal de esta última empresa porque en lo sucesivo va a explotar esa actividad ella misma con su propio personal». Es difícil expresarse más nítidamente respecto a la cuestión de fondo objeto de la cuestión prejudicial planteada.

Se podría pensar que esta importante Sentencia es totalmente innovadora, pero, aunque pueda parecerlo, en realidad no lo es tanto, porque está extrayendo las consecuencias lógicas de la concurrencia del supuesto de hecho más típico de la normativa sucesoria en su sentido interpretativo y tipológico general y clásico (art. 1 de la Directiva 2001/23/CE) (v.gr., STJUE de 26 de septiembre de 2000, Asunto Didier Meyeur, reversión de una actividad de servicio de publicidad e información al ente público local). En primer lugar, hay transmisión de una entidad económica materializada; en segundo lugar, es irrelevante la propiedad o titularidad de los bienes e instalaciones afectos al ejercicio de la actividad; en tercer lugar, la normativa sucesoria se aplica en los supuestos en que el cesionario sea una Administración Pública o un ente público en conexión con empresas o entes privados con los cuales se contrate la gestión de un servicio público. A mayor abundancia de argumentos, la reversión del servicio se realiza precisamente para continuar su ejercicio pero en régimen de gestión directa por la entidad pública a la cual revierte la actividad, lo cual es una consecuencia necesaria de que el servicio público objeto de la contratación de gestión (sucesión constitutiva) no desaparece, sino que ha de continuar dado su carácter esencial para la comunidad.

Tampoco se pueden oponer sin más preceptos como el art. 308.2 de la Ley 9/2017, de 8 de noviembre, de Contratos del Sector Público (LCSP) ( «A la extinción de los contratos de servicios [no de gestión del servicio público], no podrá producirse en ningún caso la consolidación de las personas que hayan realizado los trabajos objeto del contrato como personal de la entidad contratante. A tal fin, los empleados o responsables de la Administración deben abstenerse de realizar actos que impliquen el ejercicio de facultades que, como parte de la relación jurídico laboral, le corresponden a la empresa contratista»), si su aplicación contraviene de alguna manera la Directiva 2001/23/CE, pues habría que entender que cedería paso en su aplicación en virtud del principio de primacía del Derecho comunitario y su carácter inderogable frente a la legislación del Derecho nacional ${ }^{16}$.

La del art. 308.2 LCSP se trata de una prohibición explícita de la consolidación de trabajadores que haya prestado servicios objeto del contrato de servicios para un ente del sector público en la entidad contratante. Pero los preceptos no pueden ser objeto de aplicación e interpretación aislada en el ordenamiento jurídico. Basta reparar también en la prohibición del art. 43 del ET, y es obvio que el art. 43 del ET concede un derecho de opción de los trabajadores afectados consistente en que «los trabajadores sometidos a tráfico prohibido tendrán derecho a adquirir la condición de fijos, a su elección, en la empresa cedente o cesionaria» (que puede ser un ente público). Añadiendo además una prefiguración ex lege del estatuto jurídico-protector del trabajador afectado, a saber: «Los derechos y obligaciones del trabajador en la empresa cesionaria serán los que correspondan en condiciones ordinarias a un trabajador que preste servicios en el mismo o equivalente puesto, sin bien la antigüedad se computará desde el inicio de la cesión ilegal» ${ }^{17}$. Lo que, como bien se apunta, podría chocar con los principios que regulan el acceso al empleo público (art. $23 \mathrm{CE})^{18}$. Ello no obstante, la Administración y en general los entes del sector público no se puede substraer de la aplica-

\footnotetext{
${ }^{16}$ Así lo entiende ALFONSO MELLADO, C.: «La afirmación del art. 301 TRLCSP no puede, ni impedir la aplicación del art. 44 del ET, que deviene imperativa en atención a las normas comunitarias cuya interpretación siempre ha considerado que la Administración Pública no queda eximida de las obligaciones en materia de sucesión de empresas (STCE 26-09-2000, C-175/99, asunto Mayer; STUE 29-07-2010, C-151/09, asunto UGT/FSP), ni tampoco debe entenderse como una prohibición absoluta de que la Administración asuma el personal con ciertos condicionamientos» ("La reversión a la gestión directiva de servicios públicos. Problemas laborales", en RDS, núm. 73 (2016), pág. 37).

17 Véase la STC 196/2000, de 24 de julo, relativa al despido de trabajadores después de la declaración judicial de vinculación contractual como trabajadores de la empresa cedente.

18 CASTILLO BLANCO, F. (2016): "Remunicipalización de servicios locales y situación del personal de los servicios públicos", en Revista El Cronista del Estado Social y Democrático de Derecho, núm. 58-59, lustel, febrero-marzo, epígrafe IV.2 y apartado V («La
} 
ción de la legislación laboral en su condición de empleadores. Como es sabido la cuestión se ha resuelto de manera harto insatisfactoria -sin duda- a través de la creación judicial de la figura del «indefinido no fijo» (que después pasaría a consagrarse en el art. 8.2.c) del EBEP, que incluye entre los empleados públicos al «personal laboral, ya sea fijo, por tiempo indefinido o temporal») ${ }^{19}$.

No se olvide que la sucesión o subrogación legal ex art. 44 del ET comporta, en principio el mantenimiento del estatuto regulador aplicable a los trabajadores y que el cambio de titularidad en sí mismo no se puede aducir como justificado motivo para la extinción del contrato de trabajo (Capítulo II. «Mantenimiento de los derechos de los trabajadores», artículos 3-6, de la Directiva 2001/23/CE, de 12 de marzo; y art. 44 del $\mathrm{ET}$, norma nuclear de transposición de la misma al ordenamiento jurídico interno).

En todo caso, esto no resuelve los problemas planteados una vez admitida, en su caso y con las puntualizaciones indicadas, la sucesión laboral del empleador público. En tal caso habría que distinguir dos supuestos 20 :

El primero, que se trate de una reversión para la gestión directa por la propia Administración Pública o entes públicos instrumentales, en cuyo caso el problema que se plantea es si los trabajadores fijos de plantilla de la contratista o concesionaria originaria pasarían como tales trabajadores en esa condición. En principio se podría dar la respuesta afirmativa conforme al principio sucesorio ex art. 44 del ET, esto es, el mantenimiento de la condición de fijos. Ahora bien, la adquisición de la condición de personal fijo puede entrar en colisión con las normas que al amparo del art. 23 CE exigen en el acceso al empleo público el concurso de méritos y capacidad en condiciones de igualdad. Ante lo cual podría resolverse inadecuadamente el problema reclamando la figura del trabajador indefinido no fijo, que lo coloca en una situación provisionalidad a la espera de la convocatoria de las plazas de que se trate, de manera que si la obtienen no hay problema, pues consolidan su derecho, pero si no la obtienen verían extinguido su contrato de trabajo con el abono de la indemnización. Pero, recuérdese que, como ya se ha señalado antes, la adquisición en estos casos de la condición de trabajador indefinido no fijo había sido impedida por la Disp. Adic. 26. ${ }^{a}$ de la LPGE para 2017, que expresamente establecía que no podrían adquirir la condición de empleados públicos. Situación que ha cambiado nuevamente tras la declaración de inconstitucionalidad de esta Disposición por la STC de 31 de octubre 2018 (rec. 4710/2017), si bien queda pendiente posiblemente la declaración de inconstitucionalidad de la Disp. Adic. 43. Dos de la LPGE para 2018, que prohíbe la declaración de un trabajador como indefinido no fijo sin previa declaración judicial (aspecto que, como ya se ha indicado, se recogía igualmente en la Disp. Adic. 34. Dos de la LPGE para 2017 y que también ha sido declarado inconstitucional).

En este sentido se impone la lógica jurídica de aplicar la normativa sucesoria laboral (Directiva 2001/23/ CE y art. 44 del ET) con todas sus consecuencias, de manera que se estaría ante la nueva figura jurídica del personal laboral subrogado que presta servicios en una Administración Pública. Como personal laboral subrogado hay que retener en el supuesto de que la Administración Pública decida prestar directamente el servicio público (Es lo que viene a afirmar el mismo Art. 130.3 de la Ley 9/2017, de 8 de noviembre, de Contratos del Sector Público, a cuyo tener: «En caso de que una Administración Pública decida prestar directamente un servicio que hasta la fecha venía siendo prestado por un operador económico, vendrá obligada a la subrogación del personal que lo prestaba si así lo establece una norma legal, un convenio colectivo o un acuerdo de negociación colectiva de eficacia general»).

Por otra parte, esta solución hermenéutica no deja de ser problemática por la creación de una nueva figura de personal laboral no prevista en el EBEP. Por lo demás, no se olvide que las propias reversiones no son irreversibles, pues siempre puede tomarse una válida decisión de re-privatizar (externalizar) la gestión del servicio público a través de entes privados, no incluidos en el sector público (ni siquiera en el sector público empresarial o fundacional).

El segundo supuesto consiste en que se trate de una reversión no hacia la Administración Pública o la Entidad de naturaleza pública-administrativa (sector público administrativo), sino de una sociedad mercantil pública (sector público empresarial), rigiéndose en lo principal por el Derecho privado en general (art. 106

situación jurídica de los trabajadores que se incorporan a la Administración y de aquellos que se decida prescindir de la prestación del servicio de que se trate»).

19 Puede consultarse, MONEREO PÉREZ, J. L. (2014): "Aspectos laborales de la interconexión entre Administraciones Públicas y entes instrumentales: irregularidades en la contratación y legislación de emergencia”, en Revista de Derecho Social, núm. 67, apartado 2 («Irregularidades en la contratación laboral: Fraude de Ley en la contratación laboral y cesión ilegal de trabajadores. La problemática de la adquisición de la condición de personal laboral indefinido no fijo»), págs. 16 a 29, y la bibliografía allí citada.

20 Véase, MONEREO PÉREZ, J. L. (2016): "Repercusiones laborales de los diversos instrumentos de privatización y reversión de servicios públicos", en Temas Laborales, núm. 135, pág. 251 y ss., en particular, 270 y sigs., y la bibliografía allí citada. 
de la Ley 40/2015, de 1 de octubre, de Régimen Jurídico del Sector Público); y en lo laboral por el ET (artículos 2 y 7 del EBEP, y art. 1 del ET, señaladamente el apartado 3.a) de dicha disposición estatutaria). En tal caso, no habría problemas jurídicamente relevantes para entender que la sucesión legal comportaría la asunción del personal laboral en las mismas condiciones de fijeza ostentadas con la empresa contratista o concesionaria (sosteniendo ese criterio las SSTS 18 de septiembre de 2014, rec. 2320 y 2323/2013) y el mantenimiento del estatuto jurídico aplicable a las relaciones laborales en curso. En todo caso no son pocas las normas de racionalización del sector público general (v. gr. Ley 15/2014, de 16 de septiembre, de racionalización del sector público y otras medidas de reforma administrativa, artículos 3,5, 8 y 9), autonómico (v.gr., Ley 1/2011, de 17 de febrero, de reordenación del sector público de Andalucía) y local (Ley 27/2013, de 27 de diciembre, de racionalización y sostenibilidad de la Administración Local) las que -con buen criterio en esto- establecen expresamente el principio de sucesión legal del empleador del sector público.

Una vez admitida la sucesión de empresas en el caso de la reversión de un servicio organizado para su gestión, dejando a salvo la concurrencia efectiva de los requisitos necesarios para la integración del supuesto de hecho de la normativa aplicable, el imperativo legal y la coherencia con la Directiva 2001/23/CE y el art. 44 del ET (y atendiendo al artículos 7 del EBEP y 130.3 LCSP), obliga a aplicar el régimen jurídico laboral de garantías generales previstas en ese grupo normativo regulador que integra el Derecho social comunitario y el Derecho nacional; en definitiva en las mismas condiciones legales y convencionales que se venían aplicando en la empresa contratista o concesionaria en la cual prestaban servicios con adscripción a la actividad o servicio público objeto de contrata o concesión.

En una reflexión general cabe decir que sería necesaria una reforma de lege ferenda del art. 44 del ET consistente en la introducción de un apartado específico que garantizase una mayor seguridad jurídica y la protección más eficiente de los derechos de los trabajadores en los supuestos de cambio de titularidad en contratas y concesiones administrativas. Esta nueva regulación permitiría generalizar la aplicación imperativa y modalizada del sistema de garantías del art. 44 del ET en tales supuestos sin condicionarla necesariamente a las previsiones establecidas en los convenios colectivos sectoriales. Dicha regulación de orden público laboral podría incorporar ciertas medidas de flexibilidad de adaptación en materia de responsabilidad interempresarial por obligaciones laborales y de Seguridad Social devengadas e insatisfechas (materia, ésta última, que constituye una mejora lícita respecto al estándar de garantías mínimas establecidas en la Directiva 2001/23/CEdel Consejo, de 12 de marzo de 2001, sobre la aproximación de las legislaciones de los Estados miembros relativas al mantenimiento de los derechos de los trabajadores en caso de traspasos de empresas, de centros de actividad o de partes de empresas o de centros de actividad) ${ }^{21}$.

\section{REESTRUCTURACIONES DE ENTES PÚBLICOS. LOS DESPIDOS COLECTIVOS EN EL SECTOR PÚBLICO (DISPOSICIÓN ADICIONAL 16. ${ }^{a}$ DEL ET Y NORMAS CONCORDANTES)}

Lejos de lo que sería deseable, hablar de reestructuración de los entes públicos se ha traducido en reestructuración de plantillas en sentido «fuerte» o expeditivo, es decir, despidos colectivos o por causas objetivas. Pero es que, además, la habilitación legal (disposición adicional 16. ${ }^{a}$ del ET) no ha estado exenta de problemas aplicativos de envergadura, como la experiencia jurídica ha demostrado. Hay dificultades en la invocación de la crisis económica y su concurrencia con las exigencias presupuestarias de control del déficit público como obligación legal; el período, aunque no limita en sí mismo la discrecionalidad de la Administración, le obliga a poner en la mesa de negociación la situación realmente existente atendiendo al principio de buena fe en la negociación, cuya inobservancia ha dado lugar a revocaciones abundantes de los Tribunales de Justicia por incumplimiento del principio en cuestión ${ }^{22}$.

${ }_{21}$ Conforme al art. 3, apartado 1: «Los derechos y obligaciones que resulten para el cedente de un contrato de trabajo o de una relación laboral existente en la fecha del traspaso, serán transferidos al cesionario como consecuencia de tal traspaso». Precisando en su apartado 2 que «Los Estados miembros podrán establecer que, después de la fecha del traspaso, el cedente y el cesionario sean responsables solidariamente de las obligaciones que tuvieran su origen, antes de la fecha del traspaso, en un contrato de trabajo o en una relación laboral existentes en la fecha del traspaso». Por su parte el art. 8 de la Directiva establece que «La presente Directiva no afectará a la facultad de los Estados miembros de aplicar o adoptar disposiciones legales, reglamentarias o administrativas más favorables para los trabajadores o de promover o permitir la aplicación de convenios colectivos o acuerdos celebrados entre interlocutores sociales más favorables para los trabajadores».

22 Véase PALOMAR OLMEDA, A. (2014): “El despido colectivo en el ámbito del sector público”, en RODRíGUEZ-CAMPOS, S. (dir.): El empleo público en tiempo de reformas, Madrid: Marcial Pons, pág. 191 y ss., con cita de Sentencias sobre sociedades mer- 
Tanto en el sector público fundacional y empresarial como en el sector público administrativo no cabe duda que ha incidido la supresión de la autorización administrativa previa en los despidos colectivos, en el sentido de determinar un intervencionismo administrativo menos intenso. Ahora bien, los despidos colectivos en el sector público comportan por su propia lógica interna un mayor peso de la intervención administrativa a distinto nivel o en distintos ámbitos. Al tiempo no sólo es el marco de referencia sino también -y en relación a ello- el carácter público de los fines que se pretenden, que se centrarían en la búsqueda de la mayor eficiencia de la entidad y organismo público a través de la reestructuración de plantillas laborales.

Pero es que a mayor abundancia en esta problemática, como en cualquier otra de relevancia iuslaboral en el empleo público, se plantea siempre una fuerte tensión entre el Derecho del Trabajo y el Derecho Administrativo. Es una tensión de lógicas operativas realmente existente, pero no irresoluble dependiendo de legítimas opciones de política del Derecho. La lógica de la contradicción es inherente al constitucionalismo democrático-social, con racionalidades plurales.

Por otra parte, se debe tomar en consideración el contexto de crisis económica y las estrategias de política pública de racionalización y reorganización del personal en el sector público donde en las últimas décadas se había venido produciendo una fuerte expansión de los entes públicos instrumentales (sector público instrumental), que remite a un conjunto heterogéneo de entes vinculados o dependientes de las Administraciones públicas territoriales matrices con distintas formas de personificación y régimen jurídico, como sometimiento al Derecho público o al Derecho privado. La reestructuraciones de esos entes instrumentales -difusamente llamada «administración instrumental»- se viene produciendo con un marcado rasgo de publificación en los procedimientos y lógicamente en la mayor presencia de control y decisión de autoridades administrativas, de manera, pues, más intensa que la que se opera en el sector privado tanto más con la supresión legal (reforma de 2012) de la autorización administrativa previa en los despidos colectivos ${ }^{23}$.

Como se indicó, el marco normativo coyuntural de referencia viene caracterizado por un proceso de reestructuración, racionalización y modernización del sector público administrativos y del sector público empresarial y fundacional estatal. Se debe recordar al respecto, la incidencia que ha tenido la Orden HAP/583/2012, de 20 de marzo, por la que se publica el Acuerdo del Consejo de Ministros de 16 de Marzo de 2012, por el que se aprueba el Plan de Reestructuración y Racionalización del sector público empresarial y fundacional estatal, y la Orden HAP/1816/2013, de 2 de octubre, de reestructuración del sector público estatal.

Por otra parte, hay que tener también en cuenta que la Administración puede hacer uso de las facultades extraordinarias ciertamente complejas y problemáticas previstas en el art. 32, párrafo segundo, Real Decreto Legislativo 5/2015, de 30 de octubre, por el que se aprueba el texto refundido de la Ley del Estatuto Básico del Empleado Público, a cuyo tenor: «Se garantiza el cumplimiento de los convenios colectivos y acuerdos que afecten al personal laboral, salvo cuando excepcionalmente y por causa grave de interés público derivada de una alteración sustancial de las circunstancias económicas, los órganos de gobierno de las Administraciones Públicas suspendan o modifiquen el cumplimiento de Convenios Colectivos o acuerdos ya firmados en la medida estrictamente necesaria para salvaguardar el interés público. En este caso -continúa el precepto-, las Administraciones Públicas deberán informar a las Organizaciones Sindicales de las causas de la suspensión o modificación» (Estos párrafos del artículo 32 del EBEP fueron añadidos, significativamente, por el RD-Ley 20/2012, de 13 de julio, de medidas para garantizar la estabilidad presupuestaria y de fomento de la competitividad). Se deben subrayar, a nuestros efectos, estas facultades excepcionales de los «órganos de gobierno de las Administraciones Públicas», que acentúan la «politicidad» y la «administrativización» de los procesos de reestructuración de plantillas en las Administraciones Públicas.

cantiles (STSJ Madrid, de 9 de abril de 2013, sobre Telemadrid, poniendo de relieve la conexión de las dificultades económicas con la dotación presupuestaria y la repercusión de la extinción en la viabilidad económica y empresarial del Ente Público instrumental; STSJ Valencia, de 12 de marzo de 2013, Agencia Valenciana de Movilidad, sobre la aplicación a las Administraciones Públicas del concepto de negociación de buena fe; STSJ Cataluña, de 10 de julio de 2013, obligación de documentación y su alcance; STSJ Valencia de 23 de abril de 2013, Corporación Empresarial Valenciana, negociación de buena fe; STSJ Valencia, de 4 de noviembre de 2013 , Grupo de Empresas Públicas, sometido a una unidad de dirección; STSJ Andalucía de 20 de marzo de 2013, Ayuntamiento de Jerez, finalidad de la consulta, documentación a aportar, criterios de selección de trabajadores; y un largor etcétera de pronunciamientos que alcanzan hasta la fecha actual.

23 Véase el Real Decreto 701/2013, de 20 de septiembre, de racionalización del sector público, en el que recogen determinadas disposiciones de rango reglamentario, y un Acuerdo el que se adoptan medias de reestructuración y racionalización del sector público estatal fundacional y empresarial, publicado mediante la Orden HAP/1816/2013, de 2 de octubre. En esa dirección en Proyecto de Ley de racionalización del sector público y otras medidas de reforma administrativa (621/000072). BOCG. Senado, núm. 353, 22 de mayo de 204 , pretende adoptar las medidas legislativas necesarias para implantar recomendaciones de la CORA, tanto para la reordenación del sector público institucional, como en otros ámbitos de la actividad administrativa. 
Dos consideraciones adicionales respecto la lógica interna de la institución del despido colectivo en el Sector Público:

1. ${ }^{\circ}$ La Disposición Adicional 16 a $^{\text {a }}$ del ET, regula la «Aplicación del despido por causas económicas, técnicas, organizativas o de producción en el Sector Público». Y el procedimiento regulado en la ordenación reglamentaria (RD 1483/2012, de 29 de octubre, por el que se aprueba el reglamento de los procedimientos de despido colectivo y suspensión de contratos y reducción de jornada) respecto de la Administración Pública como empleador configura un auténtico procedimiento administrativo de carácter formalizado en sentido técnico-jurídico que culmina en una decisión administrativa objeto de control judicial en el orden jurisdiccional social. Aquí el procedimiento de regulación de empleo se enmarca en la organización administrativa del personal laboral al servicio de la Administración Pública actuante (adviértase que aunque sin carácter imperativo ya el art. 69 EBEP establece que «las Administraciones Públicas podrán aprobar planes para la ordenación de sus recursos humanos», realzando que la planificación de personal en las Administraciones Públicas tendrá como objetivo contribuir a la consecución de la eficacia en la prestación de los servicios y de la eficiencia en la utilización de los recursos económicos disponibles mediante la dimensión adecuada de sus efectivos, su mejor distribución, formación, promoción profesional y movilidad).

La empresa o entidad afectada por los despidos colectivos puede ser una empresa del sector público fundacional o empresarial o una organización administrativa. En tal sentido, la Disposición adicional 16. ${ }^{a}$ ET establece que: «El despido por causas económicas, técnicas, organizativas o de producción del personal laboral al servicio de los entes, organismos y entidades que forman parte del sector público de acuerdo con el artículo 3.1 del texto refundido de la Ley 9/2017, de 8 de noviembre, de Contratos del Sector Público, por la que se transponen al ordenamiento jurídico español las Directivas del Parlamento Europeo y del Consejo 2014/23/ UE y 2014/24/UE, de 26 de febrero de 2014, se efectuará conforme a lo dispuesto en los artículos 51 y $52 . c$ ) del ET y sus normas de desarrollo y en el marco de los mecanismos preventivos y correctivos regulados en la normativa de estabilidad presupuestaria y sostenibilidad financiera de las Administraciones Públicas».

De este modo el régimen del despido colectivo resulta aplicable al sector público de empleo laboral, con mínimas adaptaciones. Se opera, así, una laboralización de las reestructuraciones del sector público. Esta aplicación prácticamente indiferenciada de la ordenación del despido colectivo en el empleo público laboral está facilitando la expulsión de los considerados excedentes de las Administraciones públicas a todos los niveles. La causa económica se entiende existente ante una acreditada situación de insuficiencia presupuestaria sobrevenida y persistente para la financiación de los servicios públicos correspondientes. Se presume iure et de iure que existe dicha insuficiencia presupuestaria persistente si se produce durante tres trimestres consecutivos. Es de realzar que la norma utiliza conceptos jurídicos indeterminados que deberán ser objeto de especificación, como la «insuficiencia» presupuestaria que remite un desequilibrio importante, y no menor y meramente transitorio, «sobrevenida», aunque su carácter «persistente» sí está fijado en términos precisos (durante tres trimestres consecutivos).

En cuanto a las causas reorganizativas se establece que se entenderá que concurren causas técnicas, cuando se produzcan cambios, entre otros en el ámbito de los medios o instrumentos de la prestación del servicio público de que se trate y causas organizativas, cuando se produzcan cambios, entre otros, en el ámbito de los sistemas y métodos de trabajo del personal adscrito al servicio público. De un modo u otro, las causas reorganizativas aplicadas a las organizaciones administrativas se vinculan con el principio de eficiencia en la gestión de las tareas administrativas y con los servicios públicos. De este modo, el empleo público laboral se aleja del principio de estabilidad que rige en el empleo público funcionarial, en su sentido de mayor contingencia y precarización de su relación de servicios profesionales.

2. ${ }^{\circ}$ Al procedimiento de despido colectivo del personal laboral al servicio de los entes, organismos y entidades públicas que forman parte del sector público, el RD 1483/2012 le dedica todo el Título III, artículos 34 a 48 . Se trata, en el fondo, de una regulación especial respecto de la general, que permite comprender su carácter diferenciador y muy detallado. Como se indica en la Exposición de Motivos del RD 1483/2012, se pretende establecer las peculiaridades del procedimiento de despido en el sector público y específicamente en el ámbito de las Administraciones Públicas, de acuerdo con lo establecido en la disposición adicional vigésima del Estatuto de los Trabajadores.

Es necesario distinguir entre dos supuestos legalmente sujetos a un régimen jurídico diferente en función de que tengan o no la consideración legal de Administraciones Públicas conforme a lo indicado en el art. 3.2 de la Ley 9/2017, de 8 de noviembre, de Contratos del Sector Público, por la que se transponen al ordenamiento jurídico español las Directivas del Parlamento Europeo y del Consejo 2014/23/UE y 2014/24/ UE, de 26 de febrero de 2014: 
$1^{\circ}$. Entes, organismos, sociedades y entidades que formen parte del sector público pero no tengan la caracterización de Administraciones Públicas. En tal caso, se aplicarán en su integridad las reglas generales establecidas en el Título I, tanto en lo relativo a la definición de las causas de los despidos colectivos como en lo concerniente al procedimiento aplicable (art. 34.3 RD 1483/2012). No obstante, para el sector público empresarial y fundacional se contemplan informaciones adicionales a las generales del régimen ordinario (art. 34.3 del Reglamento). Siendo así que la comunicación de inicio del periodo de consultas dirigida debe incluir una «memoria explicativa de las causas del despido y su relación con los principios contenidos en la Ley Orgánica 2/2012, de 27 de abril, de Estabilidad Presupuestaria y Sostenibilidad Financiera, con las medidas o mecanismos previstos en la misma o con los objetivos de estabilidad presupuestaria a que se hace referencia» (art. 38. a) del Reglamento). A estas sociedades mercantiles o fundaciones que forman parte del sector público, que no tienen naturaleza jurídico-institucional de Administración Pública les es aplicable el régimen general previsto en los artículos 51 y 52.c) del ET, de acuerdo con la Disposición Adicional 20. ${ }^{\text {a }}$ del mismo cuerpo legal (véase SSAN de 11 de febrero de 2013, JUR 2013, 85147, y 26 de abril de 2013, JUR 2013, 160462). Debe retenerse, con carácter general, el alcance del control judicial sobre la decisión empresarial, más allá de las afirmaciones del Preámbulo de la Ley $3 / 2012$, especialmente el sometimiento al principio de razonabilidad: la razonable adecuación entre las vicisitudes de la empresa y la decisión de gestión adoptada por el empresario. Al efecto entiende que «por fuerza ha de persistir un ámbito de control judicial fuera de la "causa" como hecho, no sólo por la concurrencia de los intereses constitucionales y compromisos internacionales que están en juego, sino también por aplicación de los principios generales en el ejercicio de los derechos:» a) El derecho al trabajo (art. 35) en su dimensión individual... b) La aplicación de los principios generales del Derecho común en el ejercicio de los derechos subjetivos, y muy particularmente tanto el que impone que el mismo haya de llevarse a cabo «conforme a las exigencias de la buena fe» (art. 7.1 CC), cuanto el que prohíbe el «abuso del derecho o el ejercicio antisocial del mismo» (art. 7.2). c) El juicio de razonabilidad en su triple proyección y sucesivo escalonamiento, que obliga en todo caso a excluir -como carentes de razonabilidad y por ello ilícitas- aquellas decisiones que ofrezcan patente desproporción entre el objetivo legalmente fijado y los sacrificios impuestos a los trabajadores, porque en tales supuestos la decisión adoptada por la empresa sería contraria al ejercicio del derecho con la exigible buena fe e incurría en la prohibida conducta contraria a aquélla o en lo también excluidos abuso del derecho o ejercicio antisocial del mismo. En este sentido STS de 17 de julio de 2014, rec. 32/2014, fj. 5 y 6, con cita, entre otras, STS 27 de enero de 2014 -rco. 100/13-, fj. 4; y SG 26 de marzo de 2014 -rco. 158/13, fj. 10)-.

El RDL 5/2013, Disp. Adic. 7. ${ }^{a}$, impuso a estas entidades ciertas obligaciones de información previa en procedimientos de despido colectivo. Creó una denominada «Comisión Administrativa Técnica», que asume, en no pocos aspectos, un tipo de intervención próxima a la que asumiera antes de la reforma laboral de 2012 la autoridad «laboral», aunque, como resulta obvio, no alcanza a asumir funciones autorizantes.

2. ${ }^{\circ}$ Entes, organismos y entidades que forman parte del sector público, tal y como están relacionados en el artículo 3.1 de la Ley 9/2017, de 8 de noviembre, de Contratos del Sector Público, por la que se transponen al ordenamiento jurídico español las Directivas del Parlamento Europeo y del Consejo 2014/23/UE y 2014/24/UE, de 26 de febrero de 2014, que tengan la condición de Administraciones Públicas. En tal caso, se regula por el capítulo II del Título III, artículos 35 a 48, del RD. 1483/2012, intitulado «Procedimiento de despido colectivo aplicable en las Administraciones Públicas a que se refiere el párrafo segundo de la Disposición Adicional Vigésima del Estatuto de los Trabajadores». Pero hay que tener en cuenta que el Título II juega como ordenación normativa supletoria («En lo no regulado en este Título, y en cuanto no se oponga, contradiga o sea incompatible con el mismo, será de aplicación el procedimiento general contemplado en el Título (»). Atendiendo a su régimen jurídico se puede decir que se trata de un procedimiento especial de despido colectivo.

Nótese que la reestructuración de plantillas laborales en las Administraciones Públicas tiene que realizarse mediante los correspondientes criterios para la ordenación del empleo público (art. 69 del EBEP). En dicho precepto se prevé, en efecto, que las Administraciones Públicas pueden aprobar planes para la ordenación de sus recursos humanos, incluyendo todos los aspectos relativos a las disponibilidades y necesidades de personal. En principio, a tenor de la norma, la elaboración de esos planes parece tener un carácter facultativo, por lo que la realización de despidos colectivos en las Administraciones Públicas no requiere necesariamente su previsión a través de un Plan de reordenación del personal a su servicio. Aunque lo normal sería exigir esa previsión en una actuación correcta de la Administración Pública. Dada la misma funcionalidad del periodo de consultas-negociación colectiva entre los actores sociales y la Administración, lo más coherente es pensar que ese proceso negociador debería enmarcarse en un plan de ordenación 
del empleo público. Por ello mismo, aunque con imprecisión al respecto, se establece que en los despidos colectivos por causas económicas, las Administraciones Públicas correspondientes deberán aportar como parte integrante de la documentación justificativa «El Plan de Ordenación de Recursos Humanos, en caso de que este se haya tramitado» (art. 39.5 del Reglamento). Lo que deja entrever que puede no haber sido tramitado. Lo más coherente sería, sin embargo, que se tramitara con carácter imperativo o preceptivo. Por otra parte, conforme al art. 34. 2 del Reglamento, los despidos colectivos contemplados en la disposición adicional vigésima del ET se desarrollarán en el marco de los mecanismos preventivos y correctivos regulados en la normativa de estabilidad presupuestaria y sostenibilidad financiera de las Administraciones Públicas.

Téngase en cuenta que el art. 14 del Convenio Colectivo Único para el personal laboral de la AGE prevé el establecimiento de planes de ordenación de los «recursos humanos» (organización de personas). Dichos planes serán negociados con las organizaciones sindicales representativas en los términos establecidos en la legislación vigente.

En dicho procedimiento se establecen las peculiaridades en la delimitación del umbral cuantitativonumérico de la definición (art. 35. 1 y 2). Se define el factor causal indicando que se entenderá que concurren causas económicas cuando se produzca en las mismas una situación de insuficiencia presupuestaria sobrevenida y persistente para la financiación de los servicios públicos correspondientes. Los resultados o pérdidas negativas (del régimen ordinario) se traducen aquí en desequilibrio financiero (en línea con el art. $135 \mathrm{CE}$, que establece un principio de equilibrio presupuestario y un principio de preferencia absoluta en el pago de las deudas contraídas por la Administración Pública). La situación de insuficiencia presupuestaria ha de ser sobrevenida (posterior a la aprobación de los presupuestos anuales), actual (no basada en previsiones de futuro) y persistente (esto es, no transitoria) ${ }^{24}$. En todo caso, se entenderá que la insuficiencia presupuestaria es sobrevenida y persistente si se produce durante tres trimestres consecutivos y concurran acumulativamente determinadas circunstancias adicionales previstas reglamentariamente (art. 35. $2 .^{\circ}$ y $3 .^{\circ}$ ). La insuficiencia presupuestaria ha de ser efectivamente sobrevenida y persistente para la financiación de los servicios públicos correspondientes (SSTS ROJ: 852/2015, de 24 de febrero de 2015, rco. 165/2014, que reflexiona precisamente sobre la base de los límites de déficit estructural establecidos en el art. 135.2 CE y su desarrollo expreso en la Ley Orgánica 2/2012, de 27 de abril, de Estabilidad Presupuestaria y Sostenibilidad Financiera y que es al conjunto de las Administraciones Públicas y en general a todo el sector público; 25 de junio de 2014, rec. 165/2013; 2 de diciembre de 2014, rco. 29/2014). La insuficiencia presupuestara ha de ser cierta y actual y ha de traducirse en una carencia imprevista pero duradera del soporte económico imprescindible para poder mantener los contratos laborales celebrados. Esa insuficiencia presupuestaria enlaza con la imposibilidad de financiar los servicios públicos ${ }^{25}$. Esta causa de despido debe ser objeto de una interpretación en los términos establecidos legalmente, sin que pueda desvirtuarse a través del desarrollo reglamentario. Precisamente, la STS, sala de lo Contencioso-Administrativo, de 19 de mayo de 2015 (rec. Núm. 836/2012), resuelve el recurso contencioso-administrativo interpuesto contra e RD 1483/2012, de 29 de octubre, por el que se aprueba el Reglamento de los procedimientos de despido colectivo y de suspensión de contratos y reducción de jornada. Al respecto declara que existe una discrepancia patente entre la Ley y el Reglamento que la desarrolla, por lo que la única solución ajustada a Derecho afirmar la nulidad de éste, siendo irrelevante la posible razonabilidad de la opción reglamentaria. A diferencia del Reglamento, lo que la norma legal de referencia -esto es, la disposición final 20. ${ }^{\text {a }}$ del ET- configura como causa justificativa del despido colectivo no es la mera insuficiencia presupuestaria, sino la «insuficiencia presupuestaria sobrevenida y persistente». Esta importante adjetivación está literalmente ausente en el art. 35.3 del Reglamento $y$, sobre todo, este precepto reglamentario no responde a la exigencia legal de que la insuficiencia presupuestaria sea persistente: el simple déficit presupuestario de la Administración Pública de referencia en el ejercicio anterior no implica forzosamente tal persistencia; y en cuanto a la minoración de créditos, aun cuando pueda a veces ser indicio de dicha situación, no conduce ineluctablemente a ella. Más aún, este criterio reglamentario supone una desviación del criterio legal, consistente en un dato material o sustantivo -como es la imposibilidad de financiar los servicios públicos encomendados- sustituyéndolo por un dato puramente formal (fj. $5^{\circ}$ ). En consecuencia, se tacha este desarrollo reglamentario de ultra vires, por entender que se excede manifiestamente de los previsto en la norma legal objeto de desarrollo.

24 Véase STSJA Sevilla de 7 de marzo de 2013 (AS 2013, 1925, R 26/2012), sobre Consorcios para la Unidad Territorial de Empleo, Desarrollo Local y Servicio Andaluz de Empleo.

${ }_{25}$ RODRÍGUEZ ESCANCIANO, S. (2013): Despidos y otras medidas de (re)estructuración de plantillas en el sector público, Madrid: lustel, pág. 72. 
Por su parte, se entenderá que concurren causas técnicas, cuando se produzcan cambios, entre otros, en el ámbito de los medios o instrumentos de prestación del servicio público de que se trate y causas organizativas, cuando se produzcan cambios, entre otros, en el ámbito de los sistemas y métodos de trabajo del personal adscrito al servicio público (art. 35.3). [Nótese que las causas organizativas incluyen los supuestos de externalización sin sucesión laboral del empleador -por vía legal o convencional- de actividades antes realizadas por la Administración actuante, pues de lo contrario habría que aplicar el principio de continuidad de los contratos de trabajo en curso ex art. 44 del ET]. De este modo, las causas reorganizativas están vinculadas a las condiciones de prestación del servicio público, incorporando nuevas tecnologías, procedimiento a externalizar ciertas funciones, suprimir o reducir determinados servicios, etcétera. Sin embargo, no parece que encuentre acogida en la Administración Pública estricta (a diferencia del sector privado y del sector público empresarial y funcionarial; cfr. Acuerdo del Consejo de Ministros por el que se aprueba el plan de reestructuración y racionalización del sector público empresarial y fundacional, publicado como anexo de la Orden HAP/583/2012, de 20 de marzo) las causas productivas, porque no sólo carecen de regulación concreta en la disposición adicional 16. a del ET, ni el art. 35 del Reglamento, sino también porque la eventual aplicación supletoria del art. 51 del ET sería impracticable dado que hace referencia a los cambios, entre otros, en la demanda de los productos o servicios que la empresa quiere colocar en el mercado ${ }^{26}$.

El procedimiento propiamente dicho se inicial con la comunicación por escrito de la apertura del período de consultas dirigida por el Departamento, Consejería, Entidad Local, organismo estatal de que se trate, a los representantes legales de los trabajadores en el correspondiente ámbito, así como a la autoridad laboral y al órgano competente en materia de función pública en los términos recogidos en los artículos 42 y 43, respectivamente. A dicho escrito deberá acompañarse, según la causa alegada, la documentación establecida en los artículos 38 (Documentación común a todos los procedimientos de despido colectivo), 39 (Documentación en los despidos colectivos por causas económicas) o 40 (Documentación en los despidos colectivos por causas técnicas u organizativas). En el periodo de consultas las partes deberán de negociar de buena fe (art. 44.2). La transgresión de la buena fe en la consulta-negociación colectiva ha llevado a la revocación judicial de decisiones extintivas por vulneración de este principio de buena fe que debe ser observado en todo momento en el proceso negociador. La interlocución durante el periodo de consultas corresponderá a las secciones sindicales cuando estas lo acuerden, siempre que tengan la representación mayoritaria en los comités de empresa o entre los delegados de persona, en su caso (art. 46). El plan de recolocación externa, cuando proceda, será elaborado por los correspondientes Servicios Públicos de Empleo (art. 45), sea el SEPE o el correspondiente a la Comunidad Autónoma de que se trate. El procedimiento finaliza con la comunicación de la decisión de despido colectivo al órgano competente de su respectiva Administración, haciendo acompañar, en su caso, el acuerdo colectivo que proponga suscribir o la decisión que proponga adoptar como resultado de dichas consultas, para que éste emita informe al respecto (art. 47, relativo a la comunicación de la decisión de despido colectivo en el ámbito de la Administración General del Estado y de la Administración de las Comunidades Autónomas). En los procedimientos que afecten al personal laboral de las entidades que integran la Administración Local o a los entes u organismos dependientes de ellas, éstos comunicarán a la autoridad laboral competente el resultado del periodo de consultas. Si hubiera alcanzando acuerdo, trasladará a dicha autoridad copia íntegra del mismo. En todo caso, comunicará a los representantes de los trabajadores y a la autoridad laboral la decisión sobre el despido colectivo que realiza, actualizando, en su caso, los extremos de la comunicación a que se refiere el art. 37 (art. 48, concerniente a la comunicación de la decisión de despido colectivo en el ámbito de la Administración Local).

Se comprende, pues, que la publificación se acentúa - se hace más acusada-cuando se trata del sector público administrativo. Advirtiendo de inmediato que la competencia para la toma de decisión de despido colectivo corresponderá siempre a un órgano administrativo. Corresponderá, en efecto, al Departamento, Consejería, Entidad Local, organismo o entidad de que se trate (art. 37 del Reglamento). Aparte de ello, debe comunicarse el inicio del procedimiento administrativo de despido colectivo a la autoridad laboral (art. 42 del

${ }^{26}$ Véase RODRÍGUEZ ESCANCIANO, S. (2014): "Los despidos colectivos en las Administraciones Públicas”, en MONEREO PÉREZ, J. L. (dir.), TRIGUERO MARTíNEZ, L. y GONZÁLEZ DE PATTO, R. (coords.): Las modalidades extintivas del contrato de trabajo, Granada: Comares, pág. 489 y ss. Sobre la interpretación judicial de las causas de despido colectivos en las Administraciones Públicas, puede consultarse, PURCALLA BONILLA, M. A. (2014): "La extinción colectiva de los contratos de trabajo en las Administraciones Públicas y en el sector público", en Nueva Revista Española de Derecho del Trabajo, núm. 162, pág. 37 y ss. 
Reglamento), que actuará conforme a lo previsto en el art. 6.3 del Reglamento (dará traslado de la comunicación a la entidad gestora de las prestaciones por desempleo, así como a la IPTSS a efectos de la emisión del informe a que se refiere el art. 11), y al órgano competente en materia de Función Pública (art. 43 del Reglamento; el Ministerio de Hacienda y Administraciones Públicas o autoridad equivalente en el ámbito de las Comunidades Autónomas, podrá: acordar la aplicación de la prioridad a la que se refiere el art. 41, que tendrá carácter vinculante en los términos que figuren en el acuerdo o resolución que se dicte; e igualmente emitir informe sobre el procedimiento, sobre sus causas y sobre el resto de las circunstancias derivadas del mismo. Dicho precepto puntualiza, sin embargo, que lo dispuesto en este artículo no será de aplicación en los procedimientos que afecten al personal laboral de las entidades que integran la Administración Local o a los entes u organismos dependientes de ellas; art. 43. 3). En la Administración Local, es el Alcalde y el Presidente de la Diputación provincial los que ostentan la competencia.

La terminación o finalización del procedimiento en la Administración General del Estado y en la de las Comunidades Autónomas se produce en los términos previstos en el art. 47.1 del Reglamento. Al finalizar el período de consultas-negociación, el Departamento, Consejería, organismos o entidad de que se trate comunicará al Ministerio de Hacienda y Administraciones Públicas o autoridad equivalente en el ámbito de las Comunidades Autónomas el resultado del mismo, acompañando, en su caso, el acuerdo que proponga suscribir o la decisión que proponga adoptar como resultado de dichas consultas, para que éste emita informe al respecto. Es de destacar la presencia inicial y final del Ministerio de Hacienda y Administraciones Públicas o autoridad equivalente en el ámbito de las Comunidades Autónomas, haciendo notar el refuerzo - esa mayor presencia- del intervencionismo público en los procedimientos de despido en el marco de las Administraciones Públicas en el ámbito general y autonómico. Debe subrayarse que «este informe será vinculante en el caso de la Administración del Estado y en el de otras Administraciones en las que la normativa aplicable contemple, en el ámbito de sus respectivas competencias, la obligación de emitir un informe previo y favorable a la adopción de acuerdos, convenios, pactos o instrumentos similares de los que puedan derivarse costes y obligaciones en materia de personal a su servicio», añadiendo inmediatamente que "serán nulas de pleno derecho, las decisiones o acuerdos que se alcancen sin la concurrencia de dicho requisito» (art. 47.1, último párrafo). Es ésta una intervención como verdadera autoridad administrativa, que se justifica por la necesidad de controlar y poner límites a los costes del personal afectado (incluidas las medidas indemnizatorias, cursos de formación y otros costes añadidos) (cfr. art. 47. 1 del Reglamento). Su función es materialmente «autorizante».

Por otra parte, «el Departamento, Consejería, organismo o entidad de que se trate comunicará a la autoridad laboral competente el resultado del período de consultas» (art. 47.4). Además, la ordenación legal bien claro que transcurrido el plazo de diez días de la comunicación «sin que el ente, organismo o entidad pública afectados haya comunicado la decisión de despido colectivo, se producirá la terminación del procedimiento de despido colectivo por caducidad, sin perjuicio, en su caso, de la posibilidad de iniciar un nuevo procedimiento» (art. 47.6).

En el caso de la Administración Local o de los entes u organismos dependientes de ella, el procedimiento es más simplificado. Dichos entes comunicarán a la autoridad laboral competente el resultado del período de consultas. Transcurrido el plazo de quinces días de la comunicación «sin que el ente, organismo o entidad pública afectados haya comunicado la decisión de despido, se producirá la terminación del procedimiento de despido colectivo por caducidad, sin perjuicio, en su caso, de la posibilidad de iniciar un nuevo procedimiento» (art. 48.1 y 2 del Reglamento).

En la disposición adicional $16 .^{a}$ del ET se establece una prioridad específica en atención a la modalidad contractual del trabajador en la Administración Pública, indicando que tendrá prioridad de permanencia el personal laboral fijo que hubiera adquirido esa condición de acuerdo con los principios de igualdad, mérito y capacidad, a través de un procedimiento selectivo de ingreso convocado al efecto. Lo que, como es obvio, supone otorgar prioridad a los trabajadores laborales fijos ordinarios respecto de los trabajadores indefinidos no fijos y aplicarles a los despidos de estos las reglas comunes previstas en el grupo normativo funcional integrado por los artículos 51 y 52.c) del ET. (Véase, entre otras, STSJ Galicia de 2 de mayo de 2013, AS 2013, 1134, y STSJ Castilla y León de 30 de mayo de 2013, AS 2013, 1612).

En definitiva, se trata de una regulación especial que pese a todo sigue de cerca como paradigma a imitar el régimen jurídico general estatutario (que, no se olvide, es normativa de transposición de la Directiva 98/59/CEE del Consejo, de 20 de julio de 1998, sobre despidos colectivos), el cual actúa, significativamente, como ordenación supletoria respecto de lo no contemplado y en cuanto lógicamente no se oponga, contradiga o sea incompatible con el especialmente previsto (art. 34.4). Esta regulación estaba ya originariamente 
encaminada a facilitar potencialmente que se produzcan despidos por causas de funcionamiento de las distintas Administraciones Públicas. Pero esa «facilitación» no suponía, ni ha supuesto en la práctica una vía de escape para expulsar sin más los considerados trabajadores «excedentes» de plantilla en las Administraciones Públicas.

\section{REFERENCIAS BIBLIOGRÁFICAS}

ARETA MARTíNEZ, M. y SEMPERE NAVARRO, A. V. (2017): Sucesión de empresa: contratas, subcontratas y otros supuestos. Madrid: Francis Lefebvre.

BELTRÁN DE HEREDIA RUÍZ, I. (2017): "Una reversión del servicio de comedor escolar no puede describir una sucesión de empresa? ¿Ni a la luz del caso Abler?”, en Una mirada crítica a las relaciones (Blog de Derecho del Trabajo y de la Seguridad Social). URL: https://ignasibeltran.com/2017/03/22/una-reversion-del-servicio-decomedor-escolar-no-puede-describir-una-sucesion-de-empresa-ni-a-la-luz-del-caso-abler/.

CASTILLO BLANCO, F. (2016): "Remunicipalización de servicios locales y situación del personal de los servicios públicos", en El Cronista del Estado Social y Democrático de Derecho, núm. 58-59, lustel, febrero-marzo, apartado IV («Las previsiones contenidas en la legislación contractual pública y su alcance»).

MONEREO PÉREZ, J. (1986): "Continuidad de las relaciones de trabajo en la gestión indirecta de servicios y actividades. El cambio de titularidad en las contratas y en las concesiones administrativas", en Relaciones Laborales, núm. 7.

MONEREO PÉREZ, J. L. (1999): La noción de empresa en el Derecho del Trabajo y su cambio de titularidad. Estudio del ordenamiento interno y comunitario. Madrid: Ibidem Ediciones.

MONEREO PÉREZ, J. L. (2010): "Dimensión laboral de la transmisión de empresa y nuevas formas de organización productiva", en Tribuna Social, núms. 238-239-240.

MONEREO PÉREZ, J. L. (2014): "Aspectos laborales de la interconexión entre Administraciones Públicas y entes instrumentales: irregularidades en la contratación y legislación de emergencia", en Revista de Derecho Social, núm. 67.

MONEREO PÉREZ, J. L. (2015): "Las reestructuraciones en el sector público y su incidencia en el empleo público laboral", CASTILLO BLANCO, F. A., y MONEREO PÉREZ, J. L. (dirs. y coords.): Reestructuración de las Públicas: Aspectos administrativos y laborales. Granada: Comares.

MONEREO PÉREZ, J. L. (2016): "Repercusiones laborales de los diversos instrumentos de privatización y reversión de servicios públicos", en Temas Laborales, núm. 135.

MONEREO PÉREZ, J. L. (2017): "Tratamiento jurídico-laboral de la transmisión de empresas: funciones y disfunciones ante los «casos difíciles» en la jurisprudencia reciente", en Trabajo y Derecho, núm. 5.

PALOMAR OLMEDA, A. (2014): "El despido colectivo en el ámbito del sector público", en RODRÍGUEZ-CAMPOS, S. (dir.): El empleo público en tiempo de reformas. Madrid: Marcial Pons.

PURCALLA BONILLA, M. A. (2014): "La extinción colectiva de los contratos de trabajo en las Administraciones Públicas y en el sector público", en Nueva Revista Española de Derecho del Trabajo, núm. 162.

RODRÍGUEZ ESCANCIANO, S. (2013): Despidos y otras medidas de (re)estructuración de plantillas en el sector público. Madrid: lustel.

RODRÍGUEZ ESCANCIANO, S. (2014): "Los despidos colectivos en las Administraciones Públicas", en MONEREO PÉREZ, J. L. (dir.), TRIGUERO MARTÍNEZ, L. y GONZÁLEZ DE PATTO, R. (coords.): Las modalidades extintivas del contrato de trabajo. Granada: Comares.

RODRÍGUEZ ESCANCIANO, S. (2011): "Externalización y empleo público en régimen laboral", en ORTEGA ÁLVAREZ, L. (dir.): Crisis y externalización en el sector público: ¿Solución o problema?, págs. 153-272. Madrid: INAP.

RODRÍGUEZ ESCANCIANO, S. (2015): "Reorganización y extinción de estructuras o unidades administrativas", en CASTILLO BLANCO, F. A. y MONEREO PÉREZ, J. L. (dirs. y coords.): Reestructuración de las Administraciones Públicas: Aspectos Administrativos y Laborales, págs. 343-368. Granada: Comares.

VICENTE PALACIO, A. (2016): Empresas multiservicios y precarización del empleo. El trabajador subcedido. Madrid: Atelier. 